Eskişehir Osmangazi Üniversitesi Mühendislik ve Mimarlık Fakültesi Dergisi 27(3), 213-224, 2019
Journal of Engineering and Architecture Faculty of

Eskisehir Osmangazi University 27(3), 213-224, 2019

\title{
ANTALYA İLİNDE 2012-2016 YILLARI ARASINDA YASSANMIŞ TRAFİK KAZALARININ LOGLINEER MODELLEME YÖNTEMİ İLE ANALIZi̇
}

\author{
Arzu ER ${ }^{1 *}$, Murat KARACASU2 ${ }^{2}$, Ahmet ÇOŞGUN³ , Arzu ALTIN YAVUZ ${ }^{4}$ \\ ${ }^{1}$ Akdeniz Üniversitesi T.B.M.Y.O. İnşaat Bölümü, İnşaat Teknolojisi Programı, Antalya \\ ORCID No : https://orcid.org/0000-0003-4433-1410 \\ 2Eskişehir Osmangazi Üniversitesi Müh.Mim.Fak. İnşaat Müh.Bölümü, Eskişehir \\ ORCID No: https://orcid.org/0000-0001-9721-0984 \\ ${ }^{3}$ Akdeniz Üniversitesi T.B.M.Y.O. Elek.ve Enerji Bölümü, Antalya \\ ORCID No : https://orcid.org/0000-0002-0243-5476 \\ ${ }^{4}$ Eskişehir Osmangazi Üniversitesi Fen Edebiyat Fakültesi İstatistik Bölümü, Eskişehir \\ ORCID No: https://orcid.org/0000-0002-3277-740X
}

\begin{tabular}{l}
\hline Anahtar Kelimele \\
\hline Trafik \\
Kaza \\
Antalya \\
Loglineer
\end{tabular}

\section{Öz}

Tüm dünyada olduğu gibi Türkiye'de de trafik kazaları, sebep olduğu maddi ve manevi kayıplar nedeniyle sürekli olarak gündemdeki yerini korumaktadır. Insan, yol, araç ve çevre koşulları gibi etkenlerden bir veya birkaç etkenin bir araya gelmesiyle, telafi edilebilen maddi kazalar veya telafisi mümkün olmayan ölümlü kazalar meydana gelebilmektedir. Trafik kazalarının sayısını ve etkilerini en aza indirebilmek için ülkeler bu konularda çeşitli stratejiler ve uygulamalar geliştirmektedir. Genel olarak trafik kazalarını azaltabilmek, kazaya sebep olan etkenlerin tespit edilip ortadan kaldırılmasıyla mümkün olabilmektedir. Bu çalıșmada 2012 ile 2016 yılları arasında Antalya ili ve ilçelerinde yașanmıș, ölümlü, yaralanmalı ve maddi hasarlı olmak üzere toplam 30.232 adet trafik kazasına ait veriler incelenmiştir. Yöntem olarak kategorik değişkenlerin etkileşimlerine ait hipotez testlerinin yapıldığı loglineer modelleme ve uyum analizi kullanılmıș, sonuçta değişkenlerin ikili ya da üçlü etkileşimlerinin kaza olușumu üzerindeki etkileri değerlendirilmiștir. Çalışmanın amacı, Antalya ilinde, trafik güvenliğinin sağlanması için, kazaya etken olan değişkenlerin etkileșimlerinin önemini ortaya koyarak, önleyici tedbirlerin alınmasını sağlamaktır. Bu șekilde kazaların en aza indirgendiği, sürdürülebilir ulaştırma faaliyetleri sağlanmış olacaktır. Analiz sonuçlarına göre, Antalya bölgesinde, bölünmüş yol tipi ve asfalt kaplama ile tek yön yol tipi ve asfalt kaplama olan yerlerde trafik kazalarının olduğu belirlenmiştir. Kaza yeri ve kaza oluş biçimi ile kaza yeri ve trafik lambası durumu arasında anlamlı ilişsi olduğu belirlenmiștir.

\section{ANALYSIS OF THE TRAFFIC ACCIDENTS OF ANTALYA PROVINCE BETWEEN 2012-2016 WITH LOG-LINEAR ANALYSIS}

\begin{tabular}{l}
\hline Keywords \\
\hline Traffic \\
Accidents \\
Antalya \\
Log-Linear
\end{tabular}
\begin{abstract}
All over the world as well as in traffic accidents in Turkey, due to the material and spiritual losses caused continuously maintain its place on the agenda. Human, road, vehicle and environmental conditions, such as a combination of one or several factors combined, can be compensated material accidents or irreparable fatal accidents can occur. In order to minimize the number and impact of traffic accidents, countries develop various strategies and practices on these issues. Generally, it is possible to reduce the traffic accidents by determining and eliminating the factors causing the accident. In this study, a total of 30,232 traffic accidents, including fatalities, injuries and material damage, were observed between 2012 and 2016 in Antalya and its districts. As a method, loglinear modeling and correspondence analysis were used for the hypothesis testing of the categorical variables. Finally, the effects of binary or multiple interactions of variables on the occurrence of accidents were evaluated. The aim of the study is to provide the safety of traffic in Antalya province by demonstrating the importance of the
\end{abstract}

\footnotetext{
*Sorumlu yazar; e-posta : arzubodurer@gmail.com
} 
interaction of the variables affecting the accident, and taking preventive measures. In this way, sustainable transport activities will be ensured, where accidents are minimized. According to the results of the analysis, it was determined that there were traffic accidents in the Antalya region where there were split road type and asphalt pavement and one way road type and asphalt pavement. It was determined that there was a significant relationship between accident site and accident type and accident site and traffic light status.

\begin{tabular}{llll}
\hline Araştırma Makalesi & & Research Article & $: 22.05 .2019$ \\
Başvuru Tarihi & $: 22.05 .2019$ & Submission Date & $: 16.10 .2019$ \\
Kabul Tarihi & $: 16.10 .2019$ & Accepted Date & \\
\hline
\end{tabular}

\section{Giriş}

Ulaşım insanoğlunun en temel ihtiyaçlarındandır. İnsan ve yük taşıması için yol ve araçlara ihtiyaç duyulmuş, bu ihtiyaçlar hızla gelişen teknolojiyle giderilmeye çalışılmıştır. Ülkelerde, teknolojinin ve gelişmişliğin derecesini en iyi yansıtan ölçek niteliğinde olan ulaşım kalitesini iyileştirmeler yönünde sürekli çalışmalar yapılmaktadır. Gelişmiş ülkelerde ulaşım sektörüne yatırım yapılırken aynı zamanda ulaştırma alanındaki araştırma geliştirme faaliyetlerine de bütçe ayrıldığından, az gelişmiş veya gelişmekte olan ülkelere göre daha az kaza, yaralanma ve ölüm olayı yaşanmaktadır. Dünya Sağlık Örgütü verilerine göre; trafik kazalarında ölüm oranının, yüksek gelirli ülkelerde $\% 8.7$, orta gelirli ülkelerde $\% 20.1$ ve düşük gelirli ülkelerde \%18.3 olduğu görülmektedir (World Health Organization, 2013).

Dünya genelinde ölüm nedenleri sıralamalarında, trafik kazaları nedeniyle ölüm ilk sıralarda yerini almaktadır. Ortalama, yılda 1.24 Milyondan fazla kişi, günde de 3700'den fazla kişi hayatını kaybetmekte ve 20-50 Milyon arasındaki kişi yaralanmakta veya sakat kalmaktadır. Türkiye'nin de içinde yer aldığı gelişmekte olan ülkeler, dünyadaki taşıtların yarısına sahip olmasına karşın, trafik kazalarındaki ölümlerin \%80'i bu ülkelerde meydana gelmektedir (Kaygısız ve Sümer; 2017). Araç sayısı ve gidilen kilometre dikkate alındığında ülkemizde, Avrupa Birliği (AB) ortalamasından 6-11 kat daha fazla ölümlü kaza meydana geldiği görülmektedir. Resmi istatistikler ve trafik güvenliği raporlarına göre, 2015 yılında Türkiye'de trafik kazalarında 7.530 kişi hayatını kaybetmiş ve 304.421 kişi yaralanmıştır (Türkiye İstatistik Kurumu, 2019)

Ulaşım kalitesinde gelişmiş ülkeler seviyesine gelinebilmesi için, güvenli ve hızlı ulaşımın aynı zamanda konforlu ve çevreyi en az kirletecek şekilde sağlanması gerekmektedir. Yapılan uygulamaların bazen ulaşımdaki güvenliği sağlayamadığı ya da yetersiz kaldığı, o noktada sıklıkla yaşanılan trafik kazaları ile kendini göstermektedir. $\mathrm{Bu}$ durumda yapılması gereken; kazaların nedenlerinin iyi analiz edilmesi ve bu nedenlerin ortadan kaldırılmasına yönelik çalışmalar gerçekleştirilmesidir.
Trafik kazaları, kazaya neden olan değişkenlerin insan, yol, çevre gibi çok çeşitli olması ve sonucunda da toplumu ekonomik, sosyal, psikolojik gibi birçok yönden etkilemesi nedeniyle, ilgili tüm disiplinlerin birlikte ve etkileşim halinde çalışarak çözüme kavuşturulması gereken toplumsal bir sorundur. Dünyada ve Türkiye'de bu sorunun çözümüne yönelik yürütülen akademik çalışmaların çoğunda kazaya neden olan değişkenlerin tespiti için analizler yapıldığı ve sonuç olarak; ileri yaştaki sürücülerin sürücü lisanslarında kısıtlamaya gidilmesi (Asbridge, Poulin ve Donato, 2005), trafiğin yoğun olduğu gün ve saatlerde denetimlerin arttırılması (Bagloee ve Asadi, 2016) gibi öneriler geliștirildiği görülmektedir.

Dünyada ve ülkemizde kazaların nedenleri üzerine yapılan çalışmalarda trafik kazaları ile ilgili pek çok değişken incelenmiştir. Kavşaklarda EDS'nin (Elektronik Denetleme Sistemi) olup olmamasının kaza sayısı üzerinde etkisinin olmadığı (Kaygısız ve Sümer, 2017); sürücülere uygulanan ceza miktarının artmasının kaza sayısını azaltmadığı, aksine arttırabildiği (Bayata ve Hattatoğlu, 2010); kadın sürücü oranlarının bir ilde artması ile o ilde trafik kazalarının da arttığı (Delice, 2012); sürücü dikkatsizliğinin tatil günlerinde arttığı, gündüz erkeklerin daha fazla kazaya karıştığl, kadınların daha çok ölümlü/ yaralanmalı kazalara karıştığı (Olmuş ve Erbaş, 2012); sürücü yaşı, hava durumu, mevsim, yolun geometrik yapısı, sürücü eğitimi ve araç cinsi değişkenlerinin trafik kazası oluşumunda etkin olarak rol oynadığı (Çelik ve Senger, 2014); kazaların sıklıkla yerleşim yeri dişında, gündüz, açık havada meydana geldiği (Doğrul, Akay ve Kurt, 2015); kent içi asfalt kaplamalı yollarda meydana gelen kazaların yaralanmalı kazalar olduğu, şehir içinde meydana gelen kazalarda ölümlü kazaların daha az görüldügü, aydınlatma, trafik lambası ve yaya kaldırımı olan yerlerde ölümlü kazaların daha az olduğu, emniyet kemerinin takılı olduğu durumlarda ölen sürücü sayısının daha az olduğu, günün gündüz/gece olması, kaza tipinin çok araçlı/tek araçlı olması, kaza türü, kavşağın olup olmaması gibi parametrelerin, ölümlü ve yaralanmalı kazalardaki en önemli parametreler olduğu (Tercan ve Beşdok, 2018) ve sürücü dikkatsizliğinin kazalar üzerindeki etkisinin önemli olduğu 
(Mahmoudzadeh, Razi-Ardakani, Kermanshah, 2018) gibi birçok belirleyici sonuca ulaşılmıştır.

Literatürde; kazaların analizinde kullanılabilecek farklı metodolojilerin ve kullanılabilirlik durumlarının yorumlandığı (Lord ve Mannering, 2010) çalışmalar, toplam ölü ve yaralı sayısı ve bu sayıları etkileyen trafik kazalarına ait risk faktörlerinin istatistiksel yöntemler ve modeller kullanılarak araștırıldığı çalışmalar (Ünlü, Biçer ve Özcebe, 2017), bir sorunun eldeki verilerden hareket ile modellemeye çalışan bilgisayar destekli makine öğrenmesi adı verilen tekniklerin kullanıldığı çalıșmalar (Çodur ve Tortum, 2015; Acı ve Yılmaz, 2017), trafik kazalarının en çok meydana geldiği noktaların görsel olarak harita üzerinde tespit edilebilmesine yönelik coğrafi bilgi sistemi yönteminin kullanıldığı araştırmalar (Yılmaz, Erdoğan, Baybura, Güllü, Uysal, 2007; Kabakuş, Tortum ve Çodur, 2012) bulunmaktadır.

Bu çalışmada ise 2012-2016 yılları arasında Antalya ili ve ilçelerinde meydana gelmiş 30.232 adet trafik kazasına ait tutanaklarda yer alan; kaza yeri, yol tipi, kaplama türü, yol sınıfı, hava durumu, yolun yatay düzlemdeki geometrik yapısı, yolun düșey düzlemdeki geometrik yapısı, kavşağın geometrik yapısı, geçitlerin geometrik yapısı, yol yüzeyi, trafik lambası, aydınlatma, trafik görevlisi, kazaya karışan araç sayısı, yaya yolu, kaza oluş biçimi değişkenlerinin etkileşimleri incelenmiş ve en iyi model elde edilmeye çalışılmıştır.

$\mathrm{Bu}$ çalışmada sürücü davranışlarının tek başına trafik kazaları üzerinde etkisinin olmadığı, yol şartları ve diğer sürücüler ile olan ilişkinin de etkili olabileceği öngörülmüştür. Bu sebeple çalışmaya yol şartları ve belirtilen diğer unsurlar da eklenerek sözü edilen durumların trafik kazası ile olan ilişkilerinin ölçülmesi amaçlanmıştır. Çalışma kapsamında, trafik kazalarına etki eden temel faktörleri tespit etmek amaciyla en uygun modeli belirlemek için loglineer analiz ve belirlenen en uygun modeli görsel ve yorumsal açıdan değerlendirmek için uyum analizi yöntemleri kullanılmıştır.

\section{Materyal ve Metot}

Çalışmada kullanılan veriler (2012 ile 2016 yılları arasında Antalya ili ve ilçelerinde yaşanmış, ölümlü, yaralanmalı ve maddi hasarlı trafik kazaları verileri), T.C. İçişleri Bakanlığı Emniyet Genel Müdürlüğü Trafik Eğitim ve Araştırma Dairesi Başkanlığı'ndan temin edilmiştir.

Verilere dayalı olarak yapılan istatistiksel analizlerin, en önemli aşamalarından bir tanesi değişken yapılarına göre uygulanacak analiz yöntemlerinin seçilmesidir. Bu çalışmada, kesikli veriler için yaygın olarak kullanılan çok değişkenli veri analizlerinden loglineer modelleme ve uyum analizi tercih edilmiştir. Verilere ilk aşamada loglineer modelleme uygulanmış ve sonrasında uyum analizi ile devam edilmiştir.

\subsection{Loglineer Analiz}

Kateri'ye (2010) göre; kesikli değişkenlerden elde edilen kategorik tipteki verilerin kontenjans tablolarında gösterilmesi sıklıkla kullanılmaktadır ve bu tabloların en basiti iki yönlü kontenjan tablolarıdır. Veriler genel olarak üç veya daha çok sayıda değişkenlerin oluşturduğu kontenjans tabloları ile ifade edilmektedirler. Lawal'ın (2003) belirttiği üzere çok boyutlu kontenjan tablolarında, değişkenlerin karşılıklı bağımsızlığı, koşullu bağımsızlığı ile kısmi bağımsızlığına ait hipotezler kurulmalıdır.

İki kategorik değişken arasındaki ilişkinin incelendiği kontenjans tablo analizleri, çoğu durumda yetersiz kalmaktadır. $\mathrm{Bu}$ nedenle, çok boyutlu tabloların analizlerinde kategorik değişkenlerin etkileşimlerine ait hipotez testlerinin yapıldığı loglineer analiz, çok değişkenli analizler arasında önemli bir yere sahiptir (Christensen, 1997). Kontenjans tablolarının analizinde kullanılan loglineer modelleme, sürekli dağılıma sahip faktörün bağımlı değişkenler ile açıklandığı varyans analizine benzerliği ile dikkat çekmektedir.

Loglineer analiz ile en iyi modelin bulunmasına çalışılırken, kurulan modelin anlamlılık sınamalarının da yapılmasını sağlamaktadır (Howell, 2009).

Kesikli değişkenlerden oluşan verilerin yapısının araştırılması ile değişken/ değişkenlerin kombinasyonlarının etkisinin gösterilmesinde, verilerin daha basit bir forma indirgenmesi sağlanır (Lee, 1977).

Bu çalıșmada üç boyutlu kontenjans tablolarının analizi yapıldığından, üç boyutlu kontenjans tabloları hakkında bilgi verilecektir. Loglineer modelde, göze adı verilen tablo içindeki hücre değerlerinin doğal logaritması, kategorik değişkenlerin etkilerinin ve etkileşimlerinin doğrusal bir fonksiyonu olarak modellenir. Örnek olarak sirasılla i, j ve $k$ sayıda kategoriye sahip A, B ve C değişkenleri arasındaki ilişkilerin incelenmek istendiği varsayılsın. $\mathrm{Bu}$ durumda $\mathrm{A}, \mathrm{B}$ ve $\mathrm{C}$ kategorik değişkenlerinin $\mathrm{i}=1,2, \ldots, \mathrm{I}, \mathrm{j}=1,2, \ldots, \mathrm{J}$ ve $\mathrm{k}=1,2, \ldots, \mathrm{K}$ düzeylerinin her bir kombinasyonu için oluşturulacak logaritmik doğrusal model;

$\operatorname{Ln}\left(F_{i j k}\right)=\mu+\lambda_{i}^{A}+\lambda_{j}^{B}+\lambda_{k}^{C}+\lambda_{i j}^{A B}+\lambda_{i k}^{A C}+\lambda_{j k}^{B C}+\lambda_{i j k}^{A B C}$

şeklinde ifade edilir. Bu model, içinde ortalama ana (sabit) etkiyi $(\mu)$, diğer ana etkileri, bütün olası ikili etkileşimleri ve üçlü etkileşimi içermektedir.

Modelde; 
$\operatorname{Ln}\left(F_{i j k}\right)$ : ijk gözesi için beklenen frekansın doğal logaritması,

$\mu$ : ijk gözesi için beklenen frekansların doğal logaritmalarının ortalaması (sabit terim),

$\lambda_{i}^{A}:$ A değişkeninin ana etkisi,

$\lambda_{j}^{B}$ : B değişkeninin ana etkisi,

$\lambda_{k}^{C}:$ C değişkeninin ana etkisi,

$\lambda_{i j}^{A B}:$ A ve B değişkenleri için ikinci dereceden etkileşim etkisi,

$\lambda_{i k}^{A C}: A$ ve $C$ değişkenleri için ikinci dereceden etkileşim etkisi,

$\lambda_{j k}^{B C}: \mathrm{B}$ ve $\mathrm{C}$ değişkenleri için ikinci dereceden etkileşim etkisi,

$\lambda_{i j k}^{A B C}: \quad A, B, C$ değişkenleri için üçüncü dereceden etkileşim etkisini gösterir (Agresti, 2002:204).

Verilere ait en uygun modelin seçilmesi aşamasından önce, hangi etkilerin önemli olup olmadığının araştırılması için etkilerin elenmesi aşaması gerekmektedir. Bazı eleme sonuçları araştırmacıya yeterli bilgi verebilir. Modelleme işlemi, bağımsız değişkenler arasındaki olası mümkün tüm etkileşimler ile bașlar. Eğer üç bağımsız değișken varsa, model için tek, iki ve üç yönlü tüm etkileşimler ile işleme başlanır. Olası tüm etkileri içeren en uygun daha basit bir model bulabilmek için, modellerin hiyerarşik anlamda incelenmesi ve model uygunluğuna en az katkıyı sağlayan etkileşimlerin elenmesi gerekir. $\mathrm{Bu}$ amaçla genellikle geriye doğru aşamalı eleme işlemi kullanılır. Daha yüksek dereceye sahip etkileşimler, genel olarak önce incelenir. Ĕger yüksek dereceli etkileşim, istatistiksel olarak anlamlı değilse elenir ve ikinci dereceden etkileşimler de uygun yöntemlerle incelenir. Eleme işlemi, araştırmacı tarafından kabul edilen olasılık düzeyine bağlı olarak, modele uygun veriler kabul edilemez oluncaya kadar devam eder. Bir modelin tamamen uygun olup olmadı̆̆l, her bir model için gözlenen frekanslarla beklenen frekanslar karşılaştırılarak belirlenir (Oğuzlar, 2004).

Parametre tahminleri, bağımsız değişkenlerin göreli önemini açıklamak için kullanılmaktadır. Herhangi iki gözenin, standartlaştırılmış parametre tahminlerinin mutlak büyüklük oranı, ilgili parametreler için frekansların açıklanmasında oransal önemi yansıtır (Garson, 2007).

\subsection{Uyum Analizi}

Uyum analizi; değişkenler arasındaki ilişkilerin iki veya çok boyutlu kontenjans tablolar ile incelendiği durumlarda loglineer analize yardımcl olarak kullanılmaktadır. Diğer bir deyişle, kontenjans tablo analizinin tamamlayıcısı olan çok değişkenli istatistiksel bir tekniktir. $\mathrm{Bu}$ analiz sayesinde, her bir değișkenin kategorileri arasındaki ilişkiler grafiksel olarak yorumlanabilmektedir. Kısaca, uyum analizi iki ya da daha çok kategoriye sahip veriler arasındaki uyumu incelemektedir (Bartholomew, Steele, Moustaki ve Galbraith ,2008).

Kategorik olarak elde edilen veya kategorik hale getirilen verilerin analizinde, uyum analizi kullanılır.

Uyum analizinin 2 temel amacl vardır. Bunlar, kontenjans tablosundaki satır ve sütun kategorileri arasındaki ilişkiyi grafiksel olarak göstermek ve kontenjans tablosunun boyut sayısının azaltılması şeklinde belirtilmiştir (Alpar, 2013).

Uyum analizi, kontenjans tablosunun içerdiği değişken sayısına göre adlandırılmaktadır. Kontenjans tablosundaki değişken sayısı 2 olduğunda basit uyum analizi, 3 ve daha fazla değişken olduğunda ise çoklu uyum analizi olarak adlandırılmaktadır (Özdamar, 2013).

Uyum analizin tek varsayımı, kontenjans tablosundaki sıklıkların pozitif sayılar olmasıdır. Bunun dışından değişkenlerin dağılımı açısından bir varsayımı bulunmaması tekniğin avantajıdır (Clausen, 1998).

\section{Uygulama}

Bu bölümde Antalya ili trafik kaza verileri için loglineer ve uyum analizleri, SPSS 18 programında analiz edilmiştir. Antalya İlinde 2012-2016 yılında gerçekleşen kazalara ilişkin frekans analizi Tablo 1'de verilmiştir. Buna göre, kazaya karışanların \%84,4'ü yerleşim yerinde ve \%15,6'sı yerleşim yeri dışında kazaya karıșmıştır. Antalya İli'ndeki kazaların \%58,6'sı bölünmüş yolda, \%33,0’ı da iki yönlü yolda meydana gelmiştir. Trafik kazalarının \%94,6'sı asfalt yolda olmuştur. Antalya İli'ndeki kazaların \%62,5'i cadde, $\% 21,2$ 'si de devlet yolunda meydana gelmiștir. Yine kazaların \%89,2'si düz yolda, \%86,7'si eğimsiz yolda ve \%56,9'u kavşağın olmadığı alanlarda, \%88,8'i de geçidin olmadığı alanlarda olmuştur. Benzer şekilde, trafik kazalarının \%91,6'sının açık havada meydana geldiği görülmüștür. Antalya İli'ndeki kazaların \%90,4'ü de kuru yol yüzeyinde olduğu tespit edilmiştir. Trafik kazalarının \%41,4'ü yandan çarpma şeklinde gelişmiştir. 
Antalya İli'ndeki kazaların \%90,4'ü de kuru yol yüzeyinde olduğu tespit edilmiştir. Trafik kazalarının \%41,4'ü yandan çarpma şeklinde gelişmiştir. Antalya İli'nde olan trafik kazalarının \%59,3'ü de iki aracın çarpışması şeklinde meydana gelmiştir. Trafik kazalarının \%57,7'si de yaya yolu bulunan yerlerde oluşmuştur. Yine, trafik kazalarının \%68,5'i aydınlatması olan yerlerde ve \%99,5'i de trafik görevlisinin bulunmadığı alanlarda olmuştur.

Tablo 1

Antalya İli Trafik Kaza Verilerine İlişkin Frekans Analizi

\begin{tabular}{|c|c|c|c|}
\hline Değişken & $\%$ & Değişken & $\%$ \\
\hline Kaza Yeri (KY) & & Geo. Düșey (GD) & \\
\hline Yerleşim Yeri & 84,4 & Ĕgimsiz & 86,7 \\
\hline Yerleșim Yeri Dıșı & 15.6 & Ĕğimli & 12.6 \\
\hline Yol Tipi (YT) & & Tehlikeli Eğim & 0.5 \\
\hline Bölünmüş & 58.6 & Tepe Üstü & 0.2 \\
\hline Tek yön & 7.0 & Geo. Kavşak (GK) & \\
\hline İki yön & 33.0 & Üç yön T & 10.4 \\
\hline Diğer & 1.4 & Üç yön Y & 1.5 \\
\hline Kaplama Türü (KT) & & Dört yön & 23.2 \\
\hline Asfalt & 94.6 & Dönel Kavşak & 5.7 \\
\hline Sathi Kaplama & 1.4 & Köprülü & 0.3 \\
\hline Beton & 0.2 & Dĭger & 2.0 \\
\hline Parke & 3.4 & Hemzemin & 0.1 \\
\hline Stabilize & 0.3 & Kavşak yok & 56.9 \\
\hline Toprak & 0.1 & Geo. Geçit (GG) & \\
\hline Yol Sinıfi (YS) & & Kont.lü demiryolu & 0.2 \\
\hline Devlet yolu & 21.2 & Kont.süz demiryolu & 0.4 \\
\hline Sokak & 15.2 & Okul geçidi & 0.1 \\
\hline Cadde & 62.5 & Yaya geçidi & 10.5 \\
\hline Park Alanı & 0.1 & Geçit yok & 88.8 \\
\hline Diğer & 0.2 & Hava Durumu (HD) & \\
\hline İl Yolu & 0.2 & Açık & 91.6 \\
\hline Tesis Önü & 0.1 & Sis & 0.7 \\
\hline Servis Yolu & 0.1 & Yağmur & 7.1 \\
\hline Bağlantı Yolu & 0.1 & Kar & 0.1 \\
\hline Köy Yolu & 0.1 & Sulusepken & 0.1 \\
\hline Orman Yolu & 0.1 & Dolu & 0.1 \\
\hline Geo. Yatay (GY) & & Tipi & 0.1 \\
\hline Düz & 89.2 & Rüzgar & 0.1 \\
\hline Viraj & 8.9 & Kum Firtanası & 0.1 \\
\hline Tehlikeli Viraj & 1.9 & & \\
\hline Yol yüzey (YY) & & Trafik Lamba (TL) & \\
\hline Kuru & 90.4 & Var & 15.8 \\
\hline Islak & 9.1 & Bozuk & 3.7 \\
\hline Karlı & 0.1 & Yok & 80.4 \\
\hline Buzlu & 0.1 & Aydinlatma (AY) & \\
\hline Su birikintisi & 0.1 & Var & 68.5 \\
\hline Diğger & 0.2 & Bozuk & 1.9 \\
\hline Kaza Oluş Biçimi & & Yok & 29.6 \\
\hline Karşılıklı & 6.1 & Trafik Görevli (TG) & \\
\hline Arkadan & 12.1 & Var & 0.5 \\
\hline Yandan & 41.4 & Yok & 99.5 \\
\hline Yan Yana & 1.6 & Araç sayıya göre & \\
\hline Duran Araca & 2.2 & Tek araç & 34.5 \\
\hline
\end{tabular}

\begin{tabular}{lclc} 
Zincirleme & 0.1 & İki araç & 59.3 \\
Çoklu & 0.1 & Çok araç & 6.2 \\
Engele & 5.7 & Yaya yolu (YY) & \\
Yayaya & 12.1 & Var & 57.7 \\
Hayvana & 0.3 & Yok & 42.3 \\
Takla & 9.4 & & \\
Yoldan Çıkma & 8.4 & \\
Araçtan insan & 0.3 & \\
Araçtan cisim & 0.1 & \\
\hline
\end{tabular}

\subsection{Antalya Trafik Kazaları İçin Loglineer Analiz}

\subsubsection{Model 1}

Kontenjans Tablosu verilerinin loglineer analizi için üç yaklaşım vardır. İlk aşama k-yönlü etkilerin anlamlılığının sınanmasıdır. İkinci aşama kısmi ki-kare değerlerinin incelenmesidir. Üçüncü aşama ise, geriye doğru eleme aşamasıdır. K-yönlü etkilerin ve kısmi ilişkiler için anlamlılık sınaması Tablo 2'de verilmiştir.

Tablo 2

KY, YT ve KT Verileri için k-yönlü Etkiler ve Kısmi İlişkiler

\begin{tabular}{lcccccc}
\hline Etki & K & s.d. & $\begin{array}{c}\text { Olabilirlik } \\
\text { Oran } \\
\text { Ki-Kare }\end{array}$ & $\mathbf{p}$ & $\begin{array}{c}\text { Pearson } \\
\text { Ki-Kare }\end{array}$ & p \\
\hline $\begin{array}{l}\text { K-yönlü ve } \\
\text { daha }\end{array}$ & 1 & 47 & 110373.217 & 0.001 & 323889.409 & 0.001 \\
$\begin{array}{l}\text { yüksek } \\
\text { düzeyli } \\
\text { etkiler }\end{array}$ & 2 & 38 & 1124.054 & 0.001 & 2073.582 & 0.001 \\
\hline & 15 & 21.391 & 0.125 & 35.269 & 0.002 \\
K-yönlü & 2 & 23 & 1102.663 & 0.001 & 2038.313 & 0.001 \\
etkiler & 3 & 15 & 21.391 & 0.125 & 35.269 & 0.002 \\
\hline Etki & & s.d. & Kismi Ki-Kare & $\mathbf{p}$ & \\
\hline KY*YT & & 3 & 258.643 & 0.001 & 321815.828 & 0.001 \\
KY*KT & & 5 & 276.463 & 0.001 & \\
YT*KT & & 15 & 490.067 & 0.001 & \\
KY & & 1 & 12632.655 & 0.001 & \\
YT & & 3 & 22432.776 & 0.001 & \\
KT & 5 & 74183.732 & & 0.001 & \\
\hline
\end{tabular}

Tablo 2'den görüleceği üzere, ana etkiler ( $\mathrm{k}=1)$, iki değişkenli etkileşim etkileri $(\mathrm{k}=2)$ ve üç değişkenli etkileşim etkileri $(\mathrm{k}=3)$ Pearson ki-kare değerine göre istatistiksel olarak anlamlıdır $(p<0,05)$. Ancak Olabilirlik Oran ki-kare değerine göre, üç değișkenli etkileşim etkileri $(k=3)$ anlamsızdır $(p>0,05)$. Modelde ana etkiler dışında iki değişkenli etkileşim etkileri de yer almalıdır. Uygun modelin seçimi için kısmi ilişkiler yaklaşımı sonuçları Tablo 2'de verilmiştir. Tablo 2'den anlaşılacağı üzere, tüm ana ve iki değişkenli etkileşim etkilerinin anlamlı olduğu görülmektedir $(\mathrm{p}<0,05)$. 
Geriye doğru eleme aşaması için sonuç Tablo 3'de verilmiştir.

Tablo 3

Geriye Doğru Eleme Aşaması

\begin{tabular}{|c|c|c|c|c|c|}
\hline \multicolumn{2}{|c|}{ Adım } & Etki & Ki-Kare & s.d. & $\mathrm{p}$ \\
\hline \multirow{3}{*}{\multicolumn{2}{|c|}{1 k-yönlü etki }} & $\mathrm{KY} * \mathrm{YT}$, & & & \\
\hline & & $\mathrm{KY} * \mathrm{KT}$, & 21.391 & 15 & 0.125 \\
\hline & & $\mathrm{YT}^{*} \mathrm{KT}$ & & & \\
\hline \multirow{3}{*}{$\begin{array}{l}\text { Silinen } \\
\text { Etki }\end{array}$} & 1 & KY*YT & 258.643 & 3 & 0.001 \\
\hline & 2 & $\mathrm{KY}{ }^{*} \mathrm{KT}$ & 276.463 & 5 & 0.001 \\
\hline & 3 & $\mathrm{YT}^{*} \mathrm{KT}$ & 490.067 & 15 & 0.001 \\
\hline \multirow{3}{*}{\multicolumn{2}{|c|}{2 k-yönlü etki }} & $\mathrm{KY} * \mathrm{YT}$, & & & \\
\hline & & $\mathrm{KY}^{*} \mathrm{KT}$, & 21.391 & 15 & 0.125 \\
\hline & & $\mathrm{YT}^{*} \mathrm{KT}$ & & & \\
\hline
\end{tabular}

Tablo 3'den görüldüğü gibi, üç yönlü etkinin modelden silinmesi anlamlıdır $(p>0,05)$. Parametrelerin anlamlılık sınamaları Tablo 4'te verilmiștir. Model eșitlikte verildiği gibidir;

$\operatorname{Ln} \mathrm{A}=$ Sabit terim $+\mathrm{KY}+\mathrm{YT}+\mathrm{KT}+\mathrm{KY} * \mathrm{YT}+$

$\mathrm{KY} * \mathrm{KT}+\mathrm{YT}^{*} \mathrm{KT}+\mathrm{KY}{ }^{*} \mathrm{YT}^{*} \mathrm{KY}$

Tablo 4

Parametrelerin Anlamlılık Sinaması

\begin{tabular}{llrll}
\hline & Kestirim & Std. & \multicolumn{1}{c}{$\mathrm{Z}$} & $\mathrm{p}$ \\
\hline KY*YT & -0.108 & 0.193 & -0.560 & 0.576 \\
& -0.144 & 0.198 & -0.727 & 0.467 \\
KY*KT & -0.194 & 0.112 & -1.737 & 0.082 \\
YT*KT & 1.551 & 0.195 & 7.939 & 0.001 \\
& 1.066 & 0.223 & 4.789 & 0.001 \\
KY & 1.301 & 0.107 & 12.133 & 0.001 \\
YT & 0.435 & 0.193 & 2.259 & 0.024 \\
KT & 4.093 & 0.112 & 36.604 & 0.001 \\
& 0.556 & 0.149 & 3.737 & 0.001 \\
\hline
\end{tabular}

Tablo 4 incelendiğinde, iki yönlü ilişkiler için, kaza yeri ve yol tipi ile kaza yeri ve kaplama türü parametre değerlerinin anlamsız olduğu belirlenmiștir $(p>0,05)$. Yol tipi ve kaplama türü parametre değeri anlamlı bulunmuștur $(p<0,05)$. Bölünmüș ve tek yön yol tipleri ile asfalt kaplama olması durumu arasında ilişki olduğu söylenebilir. Antalya bölgesinde, bölünmüş yol tipi ve asfalt kaplama ile tek yön yol tipi ve asfalt kaplama olan yerlerde trafik kazalarının olduğu belirlenmiştir.
Uygulanan çoklu uyum analizi sonucunda elde edilen tablo ve grafikler izleyen kısımda verilmektedir. Grafiksel gösterimdeki boyutlarla açıklanan inertia değerleri Tablo 5'de yer almaktadır. İki boyut toplam varyansın yaklaşık \% 79'unu açıklamaktadır. Şekil 1 incelendiğinde, Antalya İlinde bölünmüș yol ve asfalt kaplama tipindeki trafik kazaları yerleşim yerinde olmaktadır.

Tablo 5

KY, YT, KT için Uyum Analizi Sonuçları

\begin{tabular}{cccc}
\hline \multirow{3}{*}{ Boyut } & \multicolumn{3}{c}{ Hesaplanan Varyans } \\
& Toplam (Özdeğer) & Inertia & Varyans \% \\
\hline 1 & 1.258 & 0.419 & 41.927 \\
2 & 1.127 & 0.376 & 37.571 \\
Toplam & 2.385 & 0.795 & 79.498 \\
\hline
\end{tabular}

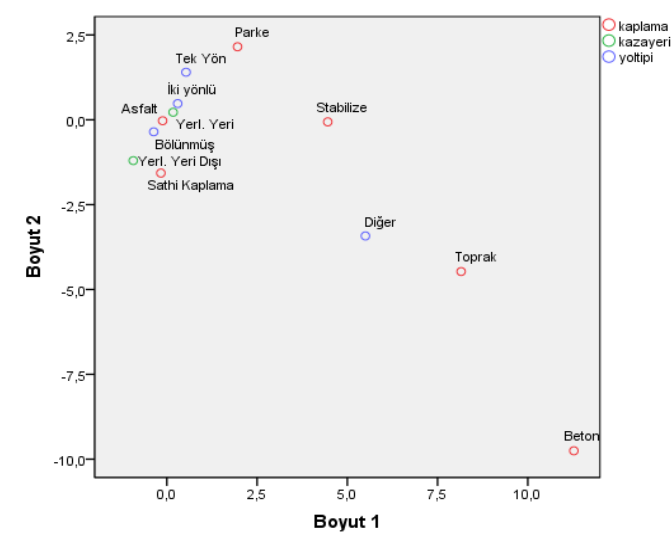

Şekil 1. KT, KY, YT için çoklu uyum grafiği

\subsubsection{Model 2}

Benzer şekilde, K-yönlü etkilerim anlamlılık sınaması Tablo 6'da verilmiștir. Tablo 6'dan görüleceği üzere, ana etkiler $(\mathrm{k}=1)$, iki değișkenli etkileșim etkileri $(\mathrm{k}=2)$ ve üç değişkenli etkileşim etkileri $(\mathrm{k}=3)$ istatistiksel olarak anlamlıdır $(\mathrm{p}<0,05)$. Modelde ana etkiler dıșında iki ve üç değişkenli etkileşim etkileri de yer almalıdır. Uygun modelin seçimi için kısmi ilişkiler yaklaşımı sonuçları Tablo 6'de verilmiștir. 
Eskişehir Osmangazi Üniversitesi Mühendislik ve Mimarlık Fakültesi Dergisi 27(3), 213-224, 2019

Tablo 6

KY, KO ve TL Verileri için k-yönlü Etkiler ve Kısmi İlișkiler

\begin{tabular}{|c|c|c|c|c|c|c|}
\hline \multirow{2}{*}{ Etki } & \multirow[b]{2}{*}{$\mathrm{K}$} & \multicolumn{3}{|c|}{ Olabilirlik Oran } & \multicolumn{2}{|c|}{ Pearson } \\
\hline & & s.d. & Ki-Kare & $\mathrm{p}$ & Ki-Kare & $\mathrm{p}$ \\
\hline \multirow{3}{*}{$\begin{array}{l}\text { K-yönlü ve daha } \\
\text { yüksek düzeyli } \\
\text { etkiler }\end{array}$} & 1 & 83 & 78622.051 & 0.001 & 220131.305 & 0.001 \\
\hline & 2 & 67 & 2919.361 & 0.001 & 3386.849 & 0.001 \\
\hline & 3 & 26 & 189.693 & 0.001 & 186.102 & 0.001 \\
\hline \multirow{3}{*}{ K-yönlü etkiler } & 1 & 16 & 75702.690 & 0.001 & 216744.455 & 0.001 \\
\hline & 2 & 41 & 2729.668 & 0.001 & 3200.747 & 0.001 \\
\hline & 3 & 26 & 189.693 & 0.001 & 186.102 & 0.001 \\
\hline$\underline{\text { Etkiler }}$ & & s.d. & \multicolumn{3}{|c|}{ Kısmi Ki-Kare } & $\mathrm{p}$ \\
\hline $\mathrm{KY}^{*} \mathrm{KO}$ & & 13 & \multicolumn{3}{|c|}{2090.616} & 0.001 \\
\hline KY*TL & & 2 & \multicolumn{3}{|c|}{26.306} & 0.001 \\
\hline $\mathrm{KO} * \mathrm{TL}$ & & 26 & \multicolumn{3}{|c|}{655.171} & 0.001 \\
\hline KY & & 1 & \multicolumn{3}{|c|}{12632.655} & 0.001 \\
\hline KO & & 13 & \multicolumn{3}{|c|}{38362.410} & 0.001 \\
\hline $\mathrm{TL}$ & & 2 & \multicolumn{3}{|c|}{24707.625} & 0.001 \\
\hline
\end{tabular}

Tablo 6'dan anlaşılacağı üzere, tüm ana ve iki değişkenli etkileşim etkilerinin anlamlı olduğu görülmektedir $(\mathrm{p}<0,05)$. Tablo 7'den görüldüğü gibi, üç yönlü etkinin modelden silinmesi anlamsızdır $(\mathrm{p}<0,05)$.

Tablo 7

Geriye Doğru Eleme Așaması

\begin{tabular}{rccccc}
\hline Adım & Etki & Ki-Kare & s.d. & p \\
\hline $\begin{array}{c}\text { Silinen } \\
\text { Etki }\end{array}$ & 1 & KY*KO*TL & 189.693 & 26 & 0,001 \\
\hline
\end{tabular}

Model eşitlikte verildiği gibidir;

Ln A= Sabit terim + KY + KO + TL + KY*KO

$+\mathrm{KY} * \mathrm{TL}+\mathrm{KO} * \mathrm{TL}+\mathrm{KY} * \mathrm{KO} * \mathrm{TL}$

Parametrelerin anlamlılı sinamaları Tablo 8'de verilmiștir. Tabloya göre, üç yönlü ilișkiler için, kaza yeri, kaza oluş biçimi ve trafik lambası durumu arasında ilișki bulunmuştur.
Tablo 8

Parametrelerin Anlamlılık Sınaması

\begin{tabular}{lllll}
\hline Etki & Kestirim & Std. Hata & $\mathrm{Z}$ & $\mathrm{p}$ \\
\hline $\mathrm{KY}$ *KO*TL & 0.069 & 0.139 & 0.495 & 0.621 \\
& 0.283 & 0.123 & 2.130 & 0.021 \\
$\mathrm{KY} * \mathrm{KO}$ & 0.311 & 0.101 & 3.094 & 0.002 \\
& -0.023 & 0.075 & -0.309 & 0.757 \\
$\mathrm{KY}$ *TL & -0.002 & 0.088 & -0.019 & 0.985 \\
$\mathrm{KO}$ *TL & -0.287 & 0.139 & -2.065 & 0.046 \\
$\mathrm{KY}$ & 0.697 & 0.063 & 10.980 & 0.001 \\
$\mathrm{KO}$ & 0.955 & 0.101 & 9.495 & 0.001 \\
$\mathrm{TL}$ & -0.244 & 0.088 & -2.771 & 0.006 \\
\hline
\end{tabular}

Antalya bölgesinde, yerleşim yeri içinde duran araca çarpma durumunda trafik lambasının olmadığı belirlenmiştir $(p<0,05)$. İki yönlü ilişkiler için, kaza yeri ve kaza oluş biçimi ile kaza yeri ve trafik lambası durumu parametre değerlerinin anlamlı olduğu belirlenmiștir $(p<0,05)$. Bölünmüș yol tipleri ile karşılıklı kaza olması durumu arasında iliş̧i olduğu söylenebilir. Antalya bölgesinde, bölünmüş yol tipi olan bölgelerde karşılıklı kaza olduğu belirlenmiştir. Benzer şekilde, Antalya bölgesi için, karşıllıklı çarpışma olan bölgelerde trafik lambasının olduğu görülmüştür.

Uygulanan çoklu uyum analizi sonucunda elde edilen inertia değerleri ve ilgili grafik izleyen kısımda verilmiştir. Inertia değerleri Tablo 9'da yer almaktadır.

Tablo 9

KY, KO, TL için Uyum Analizi Sonuçları

\begin{tabular}{|c|c|c|c|}
\hline \multirow{2}{*}{ Boyut } & \multicolumn{3}{|c|}{ Hesaplanan Varyans } \\
\hline & Toplam (Özdeğer) & Inertia & Varyans $\%$ \\
\hline 1 & 1,327 & ,442 & 44,221 \\
\hline 2 & 1,127 &, 376 & 37,556 \\
\hline Toplam & 2,453 &, 818 & \\
\hline
\end{tabular}

İki boyut toplam varyansın \%81,777'sini açıklamaktadır. Şekil 2'ye göre, Antalya İlinde yerleşim yeri içinde araç çarpışmaları olduğu yerlerde trafik lambasının olmadığı görülmüştür. Arkadan çarpma olan yerlerde trafik lambasının olduğu söylenebilir. 


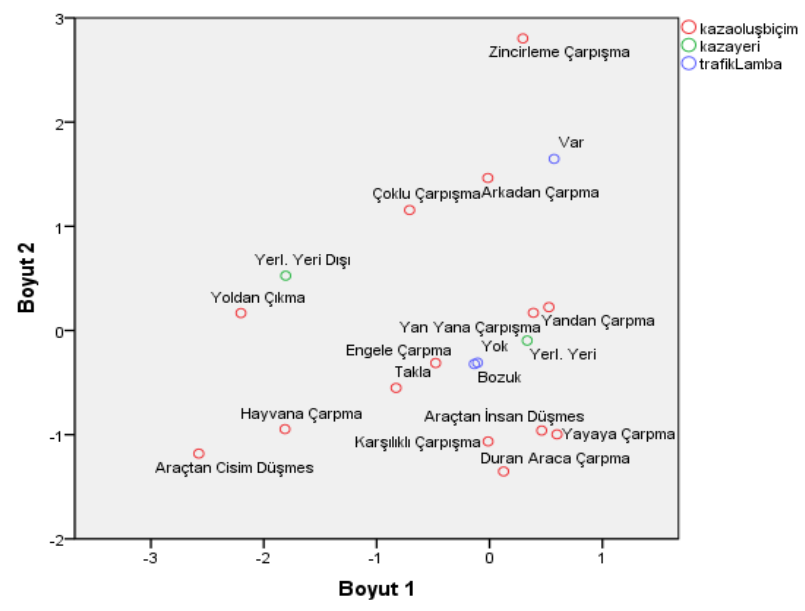

Şekil 2. KO, KY, TL için grafik

\subsubsection{Model 3}

Tablo 10'da K-yönlü ve kısmi ilişkiler için anlamlılık sınaması sonuçları verilmiştir. Tablo 14'den görüleceği üzere, ana etkiler $(\mathrm{k}=1)$ ve iki değişkenli etkileşim etkileri $(\mathrm{k}=2)$ istatistiksel olarak anlamlıdır $(\mathrm{p}<0,05)$. Modelde ana etkiler dışında iki değişkenli etkileşim etkileri de yer almalıdır. Tablo 10'den anlaşılacağı üzere, tüm ana ve iki değişkenli etkileşim etkilerinin anlamlı olduğu görülmektedir $(\mathrm{p}<0,05)$. Tablo 11'den görüldüğü gibi, üç yönlü etkinin modelden silinmesi anlamlıdır $(p>0,05)$. Model eşitlikte verildiği gibidir;

$\mathrm{Ln} \mathrm{A}=$ Sabit terim $+\mathrm{KO}+\mathrm{TL}+\mathrm{AY}+\mathrm{KO} * \mathrm{TL}+\mathrm{KO} * \mathrm{AY}+$ TL*AY

Parametrelerin anlamlılık sinamaları Tablo 12'de verilmiştir. Tablo 12'ye göre, iki yönlü ilişkiler için, trafik lambası ile aydınlatma parametre değerinin anlamlı olduğu belirlenmiştir $(p<0,05)$. Trafik lambasının olduğu ve aydınlatmanın bulunduğu parametrenin ilişki olduğu söylenebilir. Antalya bölgesi için, trafik lambası ve aydınlatmanın olduğu durumda kaza olduğu görülmüştür.

Uygulanan çoklu uyum analizi sonucunda grafiksel gösterimdeki boyutlarla açıklanan inertia değerleri Tablo 13'de yer almaktadır. İki boyut toplam varyansın yaklaşık \% 88'ini açıklamaktadır. Şekil 3 incelendiğinde, Antalya İlinde aydınlatma ve trafik lambasının olmadığ bölgelerde yayaya çarpma biçiminde kaza olduğu söylenebilir.
Tablo 10

KO, TL ve AY Verileri için k-yönlü Etkiler ve Kısmi İlişkiler

\begin{tabular}{|c|c|c|c|c|c|c|}
\hline \multirow[t]{2}{*}{ Etki } & \multirow[b]{2}{*}{$\mathrm{K}$} & \multirow{2}{*}{ s.d. } & \multicolumn{2}{|c|}{ Olabilirlik Oran } & \multicolumn{2}{|c|}{ Pearson } \\
\hline & & & Ki-Kare & $\mathrm{p}$ & Ki-Kare & $\mathrm{p}$ \\
\hline \multirow{4}{*}{$\begin{array}{l}\text { K-yönlü ve } \\
\text { daha yüksek } \\
\text { düzeyli etkiler }\end{array}$} & 1 & 125 & 86225,771 & 0,001 & 235364,474 & 0,001 \\
\hline & 2 & 108 & 3509,146 & 0,001 & 4967,362 & 0,001 \\
\hline & 3 & 52 & 46,246 & 0,699 & 42,660 & 0,819 \\
\hline & 1 & 17 & 82716,625 & 0,001 & 230397,113 & 0,001 \\
\hline \multirow{2}{*}{$\begin{array}{l}\text { K-yönlü } \\
\text { etkiler }\end{array}$} & 2 & 56 & 3462,900 & 0,001 & 4924,702 & 0,001 \\
\hline & 3 & 52 & 46,246 & 0,699 & 42,660 & 0,819 \\
\hline$\underline{\text { Etkiler }}$ & & s.d. & \multicolumn{3}{|c|}{ Kısmi Ki-Kare } & $\mathrm{p}$ \\
\hline $\mathrm{KO} * \mathrm{TL}$ & & 26 & \multicolumn{3}{|c|}{459,985} & 0,001 \\
\hline $\mathrm{KO} \mathrm{AY}^{*}$ & & 26 & \multicolumn{3}{|c|}{1083,068} & 0,001 \\
\hline TL*AY & & 4 & \multicolumn{3}{|c|}{1571,899} & 0,001 \\
\hline KO & & 13 & \multicolumn{3}{|c|}{38362,410} & 0,001 \\
\hline $\mathrm{TL}$ & & 2 & \multicolumn{3}{|c|}{24707,625} & 0,001 \\
\hline $\mathrm{AY}$ & & 2 & \multicolumn{3}{|c|}{19646,590} & 0,001 \\
\hline
\end{tabular}

Tablo 11

Geriye Doğru Eleme Aşaması

\begin{tabular}{|c|c|c|c|c|c|c|}
\hline \multicolumn{3}{|c|}{ Adım } & Etki & Ki-Kare & s.d. & $\mathrm{p}$ \\
\hline \multirow{4}{*}{1} & \multicolumn{2}{|c|}{ k-yönlü etki } & $\begin{array}{c}\mathrm{KO}^{*} \mathrm{TL}, \\
\mathrm{KO}^{*} \mathrm{AY} \\
\mathrm{TL}^{*} \mathrm{AY}\end{array}$ & 46,246 & 52 & 699 \\
\hline & \multirow{3}{*}{$\begin{array}{l}\text { Silinen } \\
\text { Etki }\end{array}$} & 1 & KO*TL & 459,985 & 26 & ,001 \\
\hline & & 2 & KO*AY & 1083,068 & 26 & 001 \\
\hline & & 3 & $\mathrm{TL}^{*} \mathrm{AY}$ & 1571,899 & 4 & ,001 \\
\hline 2 & \multicolumn{2}{|c|}{ k-yönlü etki } & $\begin{array}{c}\mathrm{KO}^{*} \mathrm{TL}, \\
\mathrm{KO}^{*} \mathrm{AY}, \\
\mathrm{TL}^{*} \mathrm{AY}\end{array}$ & 46,246 & 52 & ,699 \\
\hline
\end{tabular}

Tablo 12.

Parametrelerin Anlamlılık Sinaması

\begin{tabular}{lllll}
\hline Etkiler & Kestirim & $\begin{array}{l}\text { Std. } \\
\text { Hata }\end{array}$ & $\mathrm{Z}$ & $\mathrm{p}$ \\
\hline KO*TL & $-0,215$ & 0,150 & $-1,431$ & 0,153 \\
& 0,513 & 0,117 & 4,397 & 0,001 \\
KO*AY & 0,143 & 0,113 & 1,269 & 0,204 \\
& 0,321 & 0,096 & 3,332 & 0,001 \\
TL*AY & 0,363 & 0,109 & 3,339 & 0,001 \\
KO & 1,007 & 0,098 & 10,272 & 0,001 \\
TL & $-0,435$ & 0,090 & $-4,833$ & 0,001 \\
AY & 1,217 & 0,076 & 16,105 & 0,001 \\
\hline
\end{tabular}


Eskişehir Osmangazi Üniversitesi Mühendislik ve Mimarlık Fakültesi Dergisi 27(3), 213-224, 2019

Tablo 13.

AY, KO, TL için Uyum Analizi Sonuçları

\begin{tabular}{llll}
\hline \multirow{2}{*}{ Boyut } & \multicolumn{3}{c}{ Hesaplanan Varyans } \\
& Toplam (Özdeğer) & Inertia & Varyans \% \\
\hline 1 & 1,374 &, 458 & 45,800 \\
2 & 1,267 &, 422 & 42,230 \\
Toplam & 2,641 &, 880 & \\
\hline
\end{tabular}

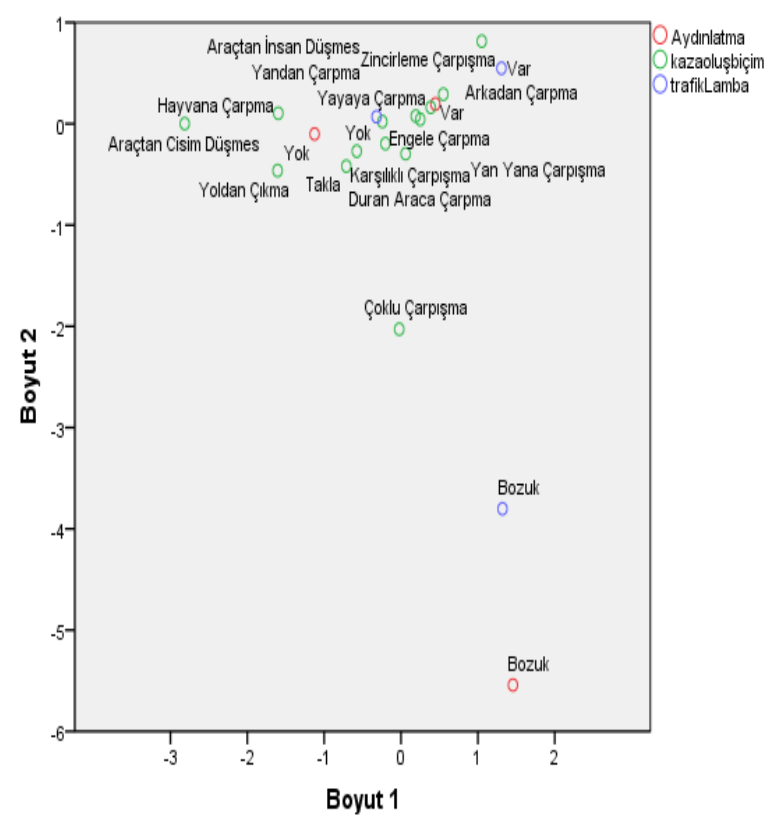

Şekil 3. AY, KO, TL için grafik

\subsubsection{Model 4}

K-yönlü etkilerin ve kısmi ilişkiler anlamlılık sınaması Tablo 14'de verilmiştir.
Tablo 14

KO, TL ve YY Verileri için k-yönlü Etkiler

\begin{tabular}{|c|c|c|c|c|c|c|}
\hline \multirow{2}{*}{ Etki } & \multirow{2}{*}{$\mathrm{K}$} & \multirow{2}{*}{ s.d. } & \multicolumn{2}{|c|}{ Olabilirlik Oran } & \multicolumn{2}{|c|}{ Pearson } \\
\hline & & & Ki-Kare & $\mathrm{p}$ & Ki-Kare & $\mathrm{p}$ \\
\hline \multirow{4}{*}{$\begin{array}{l}\text { K-yönlü ve } \\
\text { daha } \\
\text { yüksek } \\
\text { düzeyli } \\
\text { etkiler }\end{array}$} & 1 & 251 & 134908,844 & 0,001 & 737248,643 & 0,001 \\
\hline & 2 & 231 & 1202,259 & 0,001 & 1338,517 & 0,001 \\
\hline & 3 & 130 & 68,725 & 1,000 & 71,409 & 1,000 \\
\hline & 1 & 20 & 133706,585 & 0,001 & 735910,126 & 0,001 \\
\hline \multirow{3}{*}{$\begin{array}{l}\text { K-yönlü } \\
\text { etkiler }\end{array}$} & 2 & 101 & 1133,533 & 0,001 & 1267,108 & 0,001 \\
\hline & 3 & 130 & 68,725 & 1,000 & 71,409 & 1,000 \\
\hline & & s.d. & \multicolumn{3}{|c|}{ Kısmi Ki-Kare } & $\mathrm{p}$ \\
\hline KO*TL & & 26 & \multicolumn{2}{|c|}{639,731} & & 0,001 \\
\hline KO*YY & & 65 & \multicolumn{2}{|c|}{482,365} & & 0,001 \\
\hline TL*YY & & 10 & \multicolumn{2}{|c|}{22,981} & & 0,011 \\
\hline KO & & 13 & \multicolumn{2}{|c|}{38362,410} & & 0,001 \\
\hline $\mathrm{TL}$ & & 2 & \multicolumn{2}{|c|}{24707,625} & & 0,001 \\
\hline YY & & 5 & \multicolumn{2}{|c|}{70636,550} & & 0,001 \\
\hline
\end{tabular}

Tablo 14'den görüleceği üzere, ana etkiler $(\mathrm{k}=1)$ ve iki değişkenli etkileşim etkileri $(\mathrm{k}=2)$ istatistiksel olarak anlamlıdır $(\mathrm{p}<0,05)$. Modelde ana etkiler dışında iki değişkenli etkileșim etkileri de yer almalıdır. Uygun modelin seçimi için kısmi ilişkiler yaklaşımı sonuçları Tablo 14'de verilmiştir. Tablo 18'den anlaşılacağı üzere, tüm ana ve iki değişkenli etkileşim etkilerinin anlamlı olduğu görülmektedir $(p<0,05)$. Geriye doğru eleme aşaması için sonuç Tablo 15 'de verilmiștir.

\section{Tablo 15}

Geriye Doğru Eleme Așaması

\begin{tabular}{|c|c|c|c|c|c|c|}
\hline \multicolumn{3}{|c|}{ Adım } & Etki & Ki-Kare & s.d. & $\mathrm{p}$ \\
\hline \multirow[t]{4}{*}{1} & \multicolumn{2}{|c|}{ k-yönlü etki } & $\begin{array}{l}\mathrm{KO} 0^{*} \mathrm{TL}, \\
\mathrm{KO} \mathrm{O}^{*} \mathrm{Y}, \\
\mathrm{TL} \mathrm{HYY}^{2}\end{array}$ & 68,725 & 130 & 1,000 \\
\hline & \multirow{3}{*}{$\begin{array}{l}\text { Silinen } \\
\text { Etki }\end{array}$} & 1 & $\mathrm{KO} * \mathrm{TL}$ & 639,731 & 26 & ,0001 \\
\hline & & 2 & $\mathrm{KO} * \mathrm{YY}$ & 482,365 & 65 & ,001 \\
\hline & & 3 & TL*YY & 22,981 & 10 & 011 \\
\hline 2 & \multicolumn{2}{|c|}{ k-yönlü etki } & $\begin{array}{l}\mathrm{KO} 0^{*} \mathrm{TL}, \\
\mathrm{KO} \mathrm{O}^{*} \mathrm{Y}, \\
\mathrm{TL} \mathrm{Y}^{*} \mathrm{Y}\end{array}$ & 68,725 & 130 & 1,000 \\
\hline
\end{tabular}


Tablo 15'den görüldüğg̈ gibi, üç yönlü etkinin modelden silinmesi anlamlıdır $(\mathrm{p}>0,05)$. Model eşitlikte verildiği gibidir;

Ln A= Sabit terim $+\mathrm{KO}+\mathrm{TL}+\mathrm{YY}+\mathrm{KO} * \mathrm{TL}$

$+\mathrm{KO} * \mathrm{YY}+\mathrm{TL} * \mathrm{YY}$

Parametrelerin anlamlılı sinamaları Tablo $16^{\prime}$ da verilmiştir. İki yönlü ilişkiler için, kaza oluş biçimi ile yol yüzeyi parametre değerinin anlamlı olduğu belirlenmiştir $(p<0,05)$. Karşılıklı çarpışma ve kuru yüzey parametrenin ilişki olduğu söylenebilir.

Tablo 16

Parametrelerin Anlamlılık Sinaması

\begin{tabular}{lllll} 
& Kestirim & Std. Hata & $\mathbf{Z}$ & $\mathbf{p}$ \\
\hline KO*TL & $-0,299$ & 0,356 & $-0,841$ & 0,400 \\
KO*YY & 0,786 & 0,250 & 3,150 & 0,002 \\
TL*YY & $-0,087$ & 0,132 & $-0,658$ & 0,510 \\
KO & 0,396 & 0,138 & 2,869 & 0,033 \\
TL & $-0,194$ & 0,094 & $-2,064$ & 0,046 \\
YY & 3,300 & 0,094 & 35,191 & 0,001 \\
\hline
\end{tabular}

Antalya bölgesi için, karşılıklı çarpışma türü kazalar kuru zeminde olmaktadır.

Çoklu uyum analizi sonucunda elde edilen grafiksel gösterimdeki boyutlarla açıklanan inertia değerleri Tablo 17 'de yer almaktadır. İki boyut toplam varyansın yaklaşık \%76'sını açıklamaktadır.

Tablo 17

KO, TL, YY için Uyum Analizi Sonuçları

\begin{tabular}{cccc}
\hline \multirow{2}{*}{ Boyut } & \multicolumn{3}{c}{ Hesaplanan Varyans } \\
& Toplam (Özdeğer) & Inertia & Varyans \% \\
\hline 1 & 1,184 &, 395 & 39,480 \\
2 & 1,095 &, 365 & 36,506 \\
Toplam & 2,280 &, 760 & \\
\hline
\end{tabular}

Şekil 4 incelendiğinde, Antalya İlinde trafik lambasının olmadığı kuru yüzeye sahip bölgelerde karşılıklı ve yandan çarpışma türünde kaza olduğu söylenebilir.

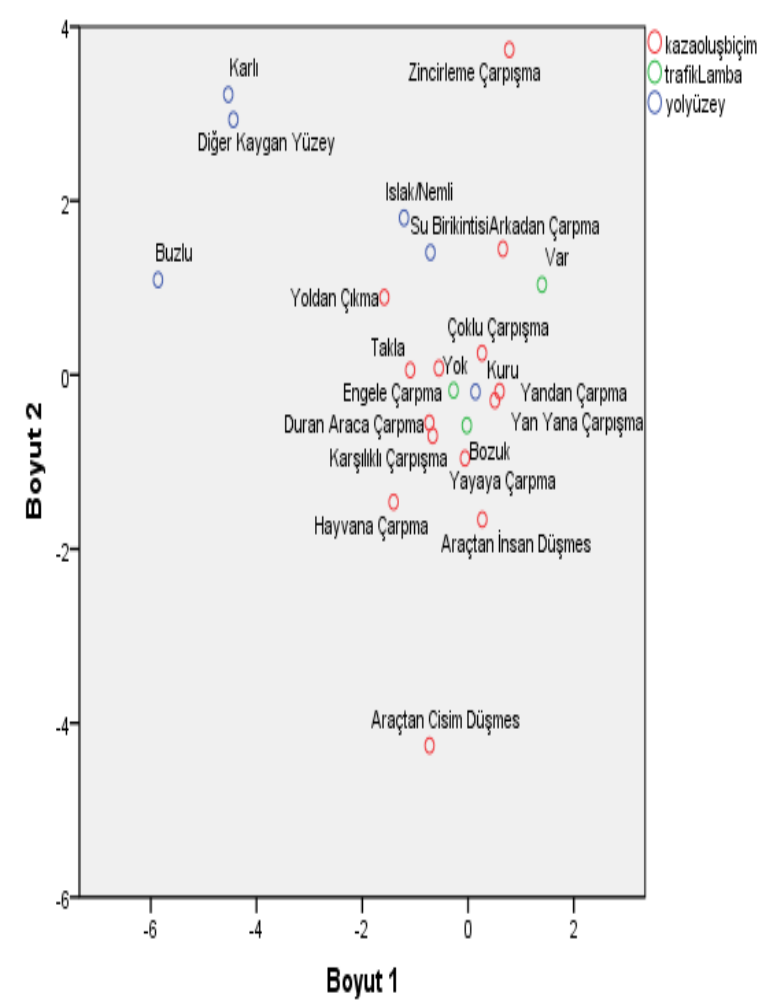

Şekil 4. KO, TL, YY için grafik

\section{Sonuç ve Öneriler}

$\mathrm{Bu}$ çalışmanın temel amacı, Antalya İlinde trafik kazalarının, trafik güvenliğinin sağlanması için, kazaya etken değişkenlerin etkileşimlerinin önemini ortaya koymaktır. Beklenmeyen durumlar olduğu zaman olan trafik kazaları için oluşturulan çok boyutlu kontenjans tablolarına, loglineer modeller uygulayarak, değişkenler arasındaki ilişki yapısını ortaya koymaktır. Bu amaç doğrultusunda, çalışmada yol ve yerleşim yerine göre elde edilen trafik kaza verileri arasındaki ilişki yapısını ortaya koymak için loglineer analizler uygulanmıştır. Yol tipi ve kaplama türü parametre değeri anlamlı bulunduğundan dolayı bölünmüș ve tek yön yol tipleri ile asfalt kaplama olması durumu arasında ilişki olduğu söylenebilir. Antalya bölgesinde, bölünmüş yol tipi ve asfalt kaplama ile tek yön yol tipi ve asfalt kaplama olan yerlerde trafik kazalarının olduğu belirlenmiştir. Çalışma sonucuyla örtüşen bulgulara rastlamak mümkündür. Özen, Genç ve Kaya (2014), ortaya koymuş oldukları çalışmada kazaların yolların teknik ve fiziksel olarak önemli sorunlar taşımasından kaynaklandığını belirtmiştir.

Antalya bölgesinde, yerleşim yeri içinde duran araca çarpma durumunda trafik lambasının olmadığı belirlenmiştir. İki yönlü ilişkiler için, kaza yeri ve kaza oluş biçimi ile kaza yeri ve trafik lambası durumu 
parametre değerlerinin anlamlı olduğu belirlenmiștir. Bölünmüş yol tipleri ile karşılıklı kaza olması durumu arasında ilişki olduğu söylenebilir. Antalya bölgesinde, bölünmüş yol tipi olan bölgelerde karşılıklı kaza olduğu tespit edilmiştir. Benzer şekilde, Antalya bölgesi için, karşılıklı çarpışma olan bölgelerde trafik lambasının olduğu görülmüştür. Antalya bölgesi için, trafik lambası ve aydınlatmanın olduğu bölgelerde kaza olduğu belirlenmiştir. Antalya bölgesinde, karşılıklı çarpışma türü kazalar kuru zeminde olmaktadır.

Uyum analizi sonuçlarının da loglineer analiz sonuçları ile örtüştüğü tespit edilmiştir. Uyum analizinin çok boyutlu kontenjans tablolarının analizinde kullanılan loglineer analizinin tamamlayıcısı bir analiz olduğu görülmektedir. Hem loglineer analizi hem de uyum analizi ile benzer sonuçlar bulunmuştur.

\section{Teşekkür}

Bu çalışmada kullanılan, 2012 ile 2016 yılları arasında Antalya ili ve ilçelerinde yaşanmış, ölümlü, yaralanmalı ve maddi hasarlı trafik kazaları verilerinin temin edilmesinde, kurumsal desteklerini esirgemeyen T.C. İçişleri Bakanlığı Emniyet Genel Müdürlüğü Trafik Eğitim ve Araştırma Dairesi Başkanlığı'na teșekkür ederiz.

\section{Çıkar Çatışması}

Yazarlar tarafından herhangi bir çıkar çatışması beyan edilmemiştir.

\section{Kaynaklar}

Acı, Ç. ve Yılmaz, A. C. (2017). Maddi hasarlı trafik kazaları için sinirsel-bulanık ağ tabanlı bir kusur tespit modeli, Fırat Üniversitesi Mühendislik Bilimleri Dergisi., 29(2), 241-250. Erişim adresi: https://dergipark.org.tr/tr/pub/fumbd/issue/3120 8/339605.

Agresti, A. (2002). Categorical data analysis (2nd ed.). New Jersey: John Wiley \& Sons. doi : https://doi.org/10.1002/0471249688

Alpar, R. (2013). Uygulamalı çok değișkenli istatistiksel yöntemler. Ankara: Detay Yayıncılık.

Asbridge, M., Poulin, C. \& Donato A. (2005). Motor vehicle collision risk and driving under the influence of cannabis: evidence from adolescents in Atlantic Canada, Accident Analysis and Prevention, 37(6), 1025-1034. doi : https://doi.org/10.1016/ j.aap.2005.05.006

Bagloee, S. A., \& Asadi, M. (2016). Crash analysis at intersections in the CBD: A survival analysis model. Transportation Research Part A: Policy and
Practice, 94, 558-572. doi : https://doi.org/10.1016/j.tra.2016.10.019

Bartholomew, D. J., Steele, F., Moustaki, I., \& Galbraith, J. I. (2008). Analysis of multivariate social science data. Florida: Chapman \& Hall/CRC Press.

Bayata, F. ve Hattatoğlu, F. (2010). Yapay sinir ağları ve çok değişkenli istatistik yöntemlerle trafik kaza modellemesi. Erzincan Üniversitesi Fen Bilimleri Enstitüsü Dergisi Cilt-Sayı: 3-2 Yıl: 2010 207-219. Erişim adresi: $\underline{\text { https://dergipark.org.tr/tr/ }}$ download/article-file/68394.

Christensen, R. (1997). Log-Linear models and logistic regression. New York: Springer Book Archive.

Clausen, S. E. (1998). Applied correpondence analysis: An introduction. California: Sage Publications.

Çelik, A.K. ve Senger, Ö. (2014). Risk factor affecting fatal versus non-fatal road traffic accidents: the case of Kars, Turkey. International Journal For Traffic and Transport Engineering, 4(3), 339-351. doi : http://dx.doi.org/10.7708/ijtte.2014.4(3).07

Çodur, M. ve Tortum, A. (2015). An artificial neural network model for highway accident predicition: a case study of Erzurum, Turkey. Promet Traffic \& Transportation, 27(3), 217-225. doi : https://doi.org/10.7307/ptt.v27i3.1551

Delice, M. (2012). Kadın sürücülerin trafik kazaları üzerindeki etkilerinin incelenmesi. $A \ddot{U}$ Sosyal Bilimler Dergisi, 12(49), 63-87. Erișim adresi: https://dergipark.org.tr/tr/download/articlefile/445286.

Doğrul, G., Akay, D. \& Kurt, M. (2015). Trafik Kazalarının Birliktelik Kuralları ile Analizi. Gazi Mühendislik Bilimleri Dergisi, 1(2), 265-284. Erişim adresi: https://dergipark.org.tr/tr/download/articlefile/302959.

Garson, G. D. (2007). Log-Linear, Logit and Probit Models. Erişim adresi: http://www2.chass.ncsu.edu/ garson/pa765/logit.htm.

Howell, D.C. (2009) Statistical methods for psychology. Canada: Wadsworth Publishing.

Kabakuş, N., Tortum, A. \& Çodur, M. Y. (2012). Erzurum ilçelerinde meydana gelen trafik kazalarının coğrafi bilgi sistemleri ile değerlendirilmesi, Ordu Üniversitesi Bilim ve Teknoloji Dergisi, 2(2), 78-92. Erişim adresi: http://btd.odu.edu.tr/files/7.pdf.

Kateri, M. (2010). Contingency table analysis: Methods and implementation using R. New York: Birkhäuser Press.

Kaygısız, Ö. ve Sümer, N. (2017). Kentsel kavşaklardaki elektronik denetim sistemlerinin trafik kazalarına etkisi: Ankara örneği. Orta Doğu Teknik Üniversitesi 
Mimarlı Fakültesi Dergisi, 34(2), 225-244. doi: https://doi.org/10.4305/METU.JFA.2017.2.3

Lawal, B. (2003). Categorical data analysis with SAS and SPSS Applicatons. London: Lawrance Erlbaum Associates.

Lee, S. K. (1977). On the asymptotic variances of u terms in loglinear models of multidimensional contingency tables. Journal of the American Statistical Association, 72(358), 412-419. doi : https://doi.org/10.1080/ $\underline{01621459.1977 .10481011}$

Lord, D. ve Mannering, F. L. (2010). The statistical analysis of crash-frequency data: a review and assessment of methodological alternatives. Transportation Research Part A Policy and Practise, 44(5), 291-305. doi : https://doi.org/10.1016/ j.tra.2010.02.001

Mahmoudzadeh, A., Razi-Ardakani, H. \& Kermanshah, M. (2018). Studying crash avoidance maneuvers prior to an impact considering different types of driver's distractions. Transportation Research Procedia. doi : https://doi.org/10.1016/j.trpro.2018.12.184

Oğuzlar, A. (2004). Hiyerarşik logaritmik doğrusal modeller arasından en uygun modelin seçimi. Öneri Dergisi, 6(21), 235-245.

Olmuş, H. ve Erbaş, S. (2012). Analysis of traffic accidents caused by drivers by using log-linear models. Promet Traffic \& Transportation, 24(6), 495504. Erişim adresi: https://pdfs.semanticscholar.org/f151/ae4afe38fcd 614f1b2aa58c21ef636237a65.pdf.

Özdamar, K. (2013). Paket programlar ile istatistiksel veri analizi. Eskişehir : Nisan Kitabevi.

Özen, E., Genç, E. \& Kaya, Z. (2014). Trafik kazalarının nedenlerine ilişkin düşünceler ve trafikte farkındalık. Optimum Journal of Economics and Management Sciences, 1(1), 1-19. Erişim adresi: https://dergipark.org.tr/tr/download/article-file/ 202149.

Tercan, E. ve Beşdok, E. (2018). Trafik kazalarına etki eden faktörler arasındaki ilişkilerin tba bi-plot analiz yöntemi ile değerlendirilmesi. Iğdır Üniversitesi Fen Bilimleri Enstitüsü Dergisi, 8(1), 103-111. https://doi.org/10.21597/jist.4078484

Türkiye İstatistik Enstitüsü. Karayolu Trafik Kaza İstatistikleri. (2015). Erişim adresi: http://www.tuik.gov.tr/PreHaberBultenleri.do?id= 21611.

Ünlü, H., Biçer, B. \& Özcebe, H. (2017). Türkiye'de 20052014 yılları arasında ölüm/yaralanma ile sonuçlanan trafik kaza verilerinin değerlendirilmesi, Turk J. Public Health, 15(2). Erişim adresi: https://dergipark.org.tr/tr/download/articlefile/346197.

World Health Organization. (2013). erişim adresi: http://www.who.int/violence injury prevention/ road safety status /2013/facts/en/)

Yılmaz, İ., Erdoğan, S., Baybura, T., Güllü, M. \& Uysal, M. (2007). Coğrafi bilgi sistemi yardımıyla trafik kazalarının analizi. Afyon Kocatepe Üniversitesi. Fen Bilimleri Dergisi, 7(2), 135-150. Erişim adresi: https://fenbildergi.aku.edu.tr/pdf/0702/7-2(143158).pdf. 